\title{
A novel missense mutation of the GRK1 gene in Oguchi disease
}

\author{
MEHMET YASIN TEKE ${ }^{1}$, MEHMET CITIRIK $^{1}$, SERKAN KABACAM $^{2}$, \\ SULEYMAN DEMIRCAN $^{1}$ and MEHMET ALIKASIFOGLU ${ }^{2}$ \\ ${ }^{1}$ SB Ankara Ulucanlar Eye Education and Research Hospital; \\ ${ }^{2}$ Department of Medical Genetics, Hacettepe University, School of Medicine, Ankara 06230, Turkey
}

Received March 6, 2016; Accepted July 1, 2016

DOI: $10.3892 / \mathrm{mmr} .2016 .5620$

\begin{abstract}
Oguchi disease is a rare form of congenital stationary night blindness with an autosomal recessive inheritance pattern. The presence of S-antigen $(S A G)$ and G-protein-dependent receptor kinase 1 (GRK1) mutations were investigated in the family members with Oguchi disease. All exons of the $S A G$ and GRKI genes were amplified by polymerase chain reaction and sequenced. The patients were shown to have characteristic clinical features of Oguchi disease. Gene analysis determined a novel GRK1 mutation c.923T $>$ C, which caused Oguchi disease in all siblings. This mutation, was demonstrated by amino acid alignment analysis to be in a phylogenetically conserved region and resulted in an amino acid change from leucine to proline at position 308 . Thus, the present study reports a novel missense mutation of GRK1 in the affected members of a consanguineous Turkish family. Homozygosity at position 308, which resides in the catalytic domain of the GRK1 gene, is the cause of Oguchi disease in this Turkish family.
\end{abstract}

\section{Introduction}

Congenital stationary night blindness (CSNB) is a group of disorders characterized by non-progressive retinal dysfunction (1). CSNB is caused by mutations in the phototransduction component or mutations in retinal signaling from the outer retina to the inner retina (1). There are two main types of CSNB with specific fundus findings, fundus albipunctatus and Oguchi disease. These disorders are inherited in an autosomal recessive pattern (2,3). A golden-brown or diffuse gray-white fundus discoloration is observed in Oguchi disease in the light adapted state. Following complete dark adaptation, the fundus returns to normal $(1,2)$. Oguchi disease is caused by the mutations in G-protein-dependent receptor kinase 1 (GRK1) (MIM:180381)

Correspondence to: Dr Mehmet Citirik, SB Ankara Ulucanlar Eye Education and Research Hospital, 59 Ulucanlar Cad, Altindag, Ankara 06230, Turkey

E-mail:mcitirik@hotmail.com

Key words: congenital stationary night blindness, gene analysis, mutation, Oguchi's disease and S-antigen (SAG) (MIM:181031) (4). Patients are divided into two groups type 1 or type 2 based on mutations in two genes, namely, $S A G$ and $G R K 1$, respectively (2).

The aim of this study was to investigate the presence of these mutations, yet to be described in a Turkish population, in family members with newly diagnosed Oguchi disease.

\section{Materials and methods}

Family history. Four family members with night blindness were referred to the Ulucanlar Eye Hospital Retina Clinic (Ankara, Turkey). Four siblings: A 12-year-old male (case 1), 14-year-old female (case 2), 16-year-old female (case 3), 19-year-old female (case 4), and their 41-year-old mother (case 5) and 44-year-old father (case 6) were examined. Cases 1-4 suffered night blindness since early childhood. The mother and father were $4^{\text {th }}$ degree relatives (first cousins) and thus had a consanguineous marriage. None of the cases had diabetes, hypertension, a history of systemic or ocular disease, nor had any undergone any surgery.

A complete ophthalmological examination was conducted including visual acuity, intraocular pressure measurement with Goldmann applanation tonometry, biomicroscobic examination and dilated pupil examination of the posterior segment.

Ethical approval. Study procedures were conducted in accordance with the Declaration of Helsinki. The study protocol was approved by The Ethical Committee of Diskapi Training and Research Hospital (Ankara, Turkey) and written informed content was obtained from all study participants. All patients were Turkish Caucasians. This study is registered as an Australian New Zealand Clinical Trials Registry (no. ACTRN 368991).

Mutation testing and Sanger sequencing. All six family members underwent mutation testing. Whole blood $(10 \mathrm{ml})$ was taken from each family member. Genomic DNA was obtained from peripheral leukocytes by ammonium acetate extraction (AppliChem GmbH, Gatersleben, Germany). To conduct Sanger sequencing, DNA samples were quantified with a NanoDrop 2000 spectrophotometer (Thermo Fisher Scientific, Inc., Wilmington, NC, USA) prior to polymerase chain reaction (PCR). Primer sequences (Table I) used for PCR reactions were determined manually by using Ensembl Database ID's ENST00000335678 (GRK1) and ENST00000409110 (SAG). 
Table I. Primer details for polymerase chain reaction.

A, SAG primer details: ENSEMBL: ENST00000409110

\begin{tabular}{|c|c|c|c|}
\hline Exon & Amplicon size (bp) & Annealing temperature $\left({ }^{\circ} \mathrm{C}\right)$ & Primer sequences \\
\hline Exon2 & 276 & 54 & $\begin{array}{l}\text { SAG-E2F: 5'-GGATCTCGTGAGTAGGTTTC-3' } \\
\text { SAG-E2R: 5'-CACTGTACTTGAAAAAGCTCC-3' }\end{array}$ \\
\hline Exon3 & 294 & 60 & $\begin{array}{l}\text { SAG-E3F: 5'-CATATTGGCCAGGCTCAAAC-3' } \\
\text { SAG-E3R: 5'-AAAGTGAGCGGTTATCTGTGAC-3' }\end{array}$ \\
\hline Exon4 & 330 & 54 & $\begin{array}{l}\text { SAG-E4F: 5'-AATGAACATGGATTACATGTG-3' } \\
\text { SAG-E4R: 5'-GTCACGTGAATTAGGTACAGG-3' }\end{array}$ \\
\hline Exon5 & 342 & 63 & $\begin{array}{l}\text { SAG-E5F: 5'-GGTTGAAAACCCGTGTTCGC-3' } \\
\text { SAG-E5R: 5'-CACATGATAAGGTGCTGCGG-3' }\end{array}$ \\
\hline Exon6 & 218 & 60 & $\begin{array}{l}\text { SAG-E6F: 5'-TAATGGAACAGCCCCTTCTG-3' } \\
\text { SAG-E6R: 5'-CCCAGCATTGGTGACAGAGT-3' }\end{array}$ \\
\hline Exon7 & 319 & 60 & $\begin{array}{l}\text { SAG-E7F: 5'-TGCAACCCCGAATAGGACAT-3' } \\
\text { SAG-E7R: 5'-CAGCCCTATGGGAAGAGGTCT-3' }\end{array}$ \\
\hline Exon8 & 359 & 60 & $\begin{array}{l}\text { SAG-E8F: 5'-GAGCATTCCTGGAGAATCTCC-3' } \\
\text { SAG-E8R: 5'-GAAACAAGCTTCCTTGCAAGG-3' }\end{array}$ \\
\hline Exon9 & 336 & 60 & $\begin{array}{l}\text { SAG-E9F: 5'-GTGTTTCAGGCCCTTCCTTAG-3' } \\
\text { SAG-E9R: 5'-CAGACCAGAGAAGTGACCTCTC-3' }\end{array}$ \\
\hline Exon10 & 431 & 60 & $\begin{array}{l}\text { SAG-E10F: 5'-ACAGGACTTCAAAACCCCAG-3' } \\
\text { SAG-E10R: 5'-GGTGTGGTAGATGCAGAGCTAAG-3' }\end{array}$ \\
\hline Exon11 & 360 & 60 & $\begin{array}{l}\text { SAG-E11F: 5'-GTCAAGTTCCCAGGCTCTTG-3' } \\
\text { SAG-E11R: 5'-CAGGGTGATGTGAAGGGAAG-3' }\end{array}$ \\
\hline Exon12 & 226 & 60 & $\begin{array}{l}\text { SAG-E12F: 5'-CTGCCCATCTGCTCTTCACC-3' } \\
\text { SAG-E12R: 5'-CTCCCAGTCATTCAGGAAAGG-3' }\end{array}$ \\
\hline Exon13 & 252 & 60 & $\begin{array}{l}\text { SAG-E13F: 5'-GATGTTGTGAGTTCGGGTGC-3' } \\
\text { SAG-E13R: 5'-CACAACTGTCCAGAAAGCAGC-3' }\end{array}$ \\
\hline Exon14 & 248 & 63 & $\begin{array}{l}\text { SAG-E14F: 5'-TGTGACTCTCCGCAGCCATAG-3' } \\
\text { SAG-E14R: 5'-CACTCCCATGCTCTGAGATGC-3' }\end{array}$ \\
\hline Exon 15 & 251 & 60 & $\begin{array}{l}\text { SAG-E15F: 5'-ACGCAGTGATCATGAACTGC-3' } \\
\text { SAG-E15R: 5'-GACTCAAAGAGGGTTTTGTGC-3' }\end{array}$ \\
\hline Exon16 & 348 & 63 & $\begin{array}{l}\text { SAG-E16F: 5'-CCTTGATCAGTTCCTTCGTTGC-3' } \\
\text { SAG-E16R: 5'-CCAGGGGAGAACAAACAAGCT-3' }\end{array}$ \\
\hline
\end{tabular}

B, GRK1 primer details: ENSEMBL: ENST00000335678

\begin{tabular}{|c|c|c|c|}
\hline Exon & Amplicon size (bp) & Annealing temperature $\left({ }^{\circ} \mathrm{C}\right)$ & Primer sequences \\
\hline Exon1/1 & 443 & 64 & $\begin{array}{l}\text { GRK1-E1/1F: 5'-TGCTCTGTCTGTGAACGCTCC-3' } \\
\text { GRK1-E1/1R: 5'-AGAAGAGTTTGGCCTGGGGG-3' }\end{array}$ \\
\hline Exon $1 / 2$ & 526 & 64 & $\begin{array}{l}\text { GRK1-E1/2F: 5'-CGGCAGACAATGACCTCCAG-3' } \\
\text { GRK1-E1/2R: 5'-AGGCACCAGCTGTTAAGGGC-3' }\end{array}$ \\
\hline Exon2 & 280 & 62 & $\begin{array}{l}\text { GRK1-E2F: 5'-CGATGCACCTAGTCCCTTTCC-3' } \\
\text { GRK1-E2R: 5'-ATGGCTCTGCCTGTGGAAAG-3' }\end{array}$ \\
\hline Exon3 & 360 & 62 & $\begin{array}{l}\text { GRK1-E3F: 5'-TCAAAACGACCAGAACGCTG-3' } \\
\text { GRK1-E3R: 5'-TCGTGAGGTTGTGCAGAGACC-3' }\end{array}$ \\
\hline Exon4 & 207 & 64 & $\begin{array}{l}\text { GRK1-E4F: 5'-TGTGCAGCCAGGGGTGACTC-3' } \\
\text { GRK1-E4R:5'-GTATGTGCAAGTGCACACAGGC-3' }\end{array}$ \\
\hline Exon5 & 291 & 62 & $\begin{array}{l}\text { GRK1-E5F: 5'-AGCATCAGTCCTGCGATTCC-3' } \\
\text { GRK1-E5R: 5'-CAGTAACGATCCCATCACTGCC-3' }\end{array}$ \\
\hline Exon6 & 353 & 62 & $\begin{array}{l}\text { GRK1-E6F: 5'-TCTGGTCTGACCACCCAAGAG-3' } \\
\text { GRK1-E6R: 5'-CCGACTCTCACAGGCTGGAC-3' }\end{array}$ \\
\hline Exon7 & 451 & 64 & GRK1-E7F: 5'-GGCTAAACGGCGCTTCCTTC-3' \\
\hline
\end{tabular}

$S A G$, S-antigen; GRK1, G-protein-dependent receptor kinase 1. 
Table II. Amino acid alterations in $S A G$ and $G R K 1$ genes.

A, SAG amino acid alterations

\begin{tabular}{|c|c|c|c|c|c|}
\hline Case & Gene region & Alteration & Condition & SNP ID & Amino acid alterations \\
\hline 1 & Exon 16 & c. $1207 \mathrm{G}>\mathrm{A}$ & Heterozygote & rs 1046974 & Val403Ile \\
\hline \multirow[t]{4}{*}{2} & Exon 16 & c. $1207 \mathrm{G}>\mathrm{A}$ & Homozygote & rs 1046974 & Val403Ile \\
\hline & Intron 4-5 & c. $181+82 A>G$ & Homozygote & rs2304777 & - \\
\hline & Intron 6-7 & c. $436-18 \mathrm{G}>\mathrm{C}$ & Homozygote & rs2304774 & - \\
\hline & Intron 9-10 & c. $733+31 \mathrm{~T}>\mathrm{G}$ & Homozygote & rs745498 & - \\
\hline 3 & Exon 16 & c. $1207 \mathrm{G}>\mathrm{A}$ & Homozygote & rs 1046974 & Val403Ile \\
\hline 4 & Exon 16 & c. $1207 \mathrm{G}>\mathrm{A}$ & Heterozygote & rs 1046974 & Val403Ile \\
\hline 5 & Exon 16 & c. $1207 \mathrm{G}>\mathrm{A}$ & Homozygote & rs 1046974 & Val403Ile \\
\hline 6 & Exon 16 & c. $1207 \mathrm{G}>\mathrm{A}$ & Heterozygote & rs 1046974 & Val403Ile \\
\hline
\end{tabular}

B, GRK1 amino acid alterations

\begin{tabular}{llllll}
\hline Case & Gene region & Alteration & Condition & SNP ID & Amino acid alterations \\
\hline 1 & Exon 3 & c.923T $>\mathrm{C}$ & Homozygote & Novel & Leu308Pro \\
2 & Exon 3 & c.923T $>\mathrm{C}$ & Homozygote & Novel & Leu308Pro \\
3 & Exon 3 & c.923T $>\mathrm{C}$ & Homozygote & Novel & Leu308Pro \\
4 & Exon 3 & c.923T $>\mathrm{C}$ & Homozygote & Novel & Leu308Pro \\
5 & Exon 3 & c.923T $>\mathrm{C}$ & Heterozygote & Novel & Leu308Pro \\
6 & Exon 3 & c.923T $>\mathrm{C}$ & Heterozygote & Novel & Leu308Pro \\
\hline
\end{tabular}

$S A G$, S-antigen; GRK1, G-protein-dependent receptor kinase 1; SNP, single nucleotide polymorphism.

Then 200 ng genomic DNA was combined with 5X Buffer (Promega Corporation, Madison, WI, USA), $0.2 \mathrm{mM}$ of each dNTP (Promega Corporation), $1.5 \mathrm{mM} \mathrm{MgCl}_{2}$ (Promega Corporation), $0.2 \mu \mathrm{M}$ of forward and reverse primers (IDT, Inc., Coralville, IA, USA), 1 unit GoTaq DNA Polymerase (Promega Corporation) and nuclease-free water up to $25 \mu \mathrm{l}$. The PCR mix was vortex mixed, centrifuged at $650 \mathrm{x} \mathrm{g}$ for 1 min, then transferred to a thermal cycler (ABI 9700; Applied Biosystems, Foster City, CA, USA). Samples were amplified with an initial heat denaturation step of $94^{\circ} \mathrm{C}$ for $5 \mathrm{~min}$; followed by 35 cycles of $94^{\circ} \mathrm{C}$ for $30 \mathrm{sec}, 54-65^{\circ} \mathrm{C}$ for $30 \mathrm{sec}$, and $72^{\circ} \mathrm{C}$ for $30 \mathrm{sec}$, and a final of extension at $72^{\circ} \mathrm{C}$ for $7 \mathrm{~min}$. Primer sequences and annealing temperatures are shown in Table I. PCR products were run on agarose gels and samples with the correct band size were purified using Wizard SV Gel and PCR Cleanup system (Promega Corporation, Madison, WI, USA). After purification, PCR products were cycle sequenced using forward primers and the BigDye Terminator v3.1 Cycle Sequencing kit (Thermo Fisher Scientific, Inc.). After cycle sequencing, products were cleaned up using ZR DNA Sequencing Clean up kit (Zymo Research, Irvine, CA, USA) and loaded onto 96-well plates of a 3130 Genetic Analyzer (Applied Biosystems). Analysis of the results was conducted using SeqScape 3 Software (Applied Biosystems).

Bioinformatics analysis. Two of the most popular bioinformatics tools [Sorting Intolerant from Tolerant (SIFT; http://sift.bii.a-star.edu.sg/) and Polymorphism Phenotyping v2
(PolyPhen-2; http://genetics.bwh.harvard.edu/pph2/)] were used to predict whether the amino acid substitutions identified in the study affect protein function. These types of tools use predictions based on the degree of conservation of amino acid residues in sequence alignments derived from closely associated sequences, and additionally the impact of the substitution on the structure and function of the protein.

\section{Results}

Patient characteristics. The family members (four siblings 12-year-old male, 14-year-old female, 16-year-old female and 19-year-old, and their 41-year-old mother and a 44-year-old father were examined. There was no history of night blindness in either the mother or the father. However, four of the family members had a history of nyctalopia since early childhood. Their visual acuity was 20/20 bilaterally and they had no refractive error. All children and their parents had normal intraocular eye pressure $(11-19 \mathrm{mmHg}$ ) values. All patient's eyes were phakic and slit-lamp examination revealed normal findings. Fundus examination of parents revealed normal findings. However, fundus images of the four children showed a characteristic golden metallic reflex in all areas of the fundus. The Mizuo-Nakamura phenomenon was demonstrated: The fundus color changed to normal after three hours of dark adaptation.

Sanger sequencing results. Sanger sequencing for two candidate genes, GRK1 and SAG was conducted. The coding regions 


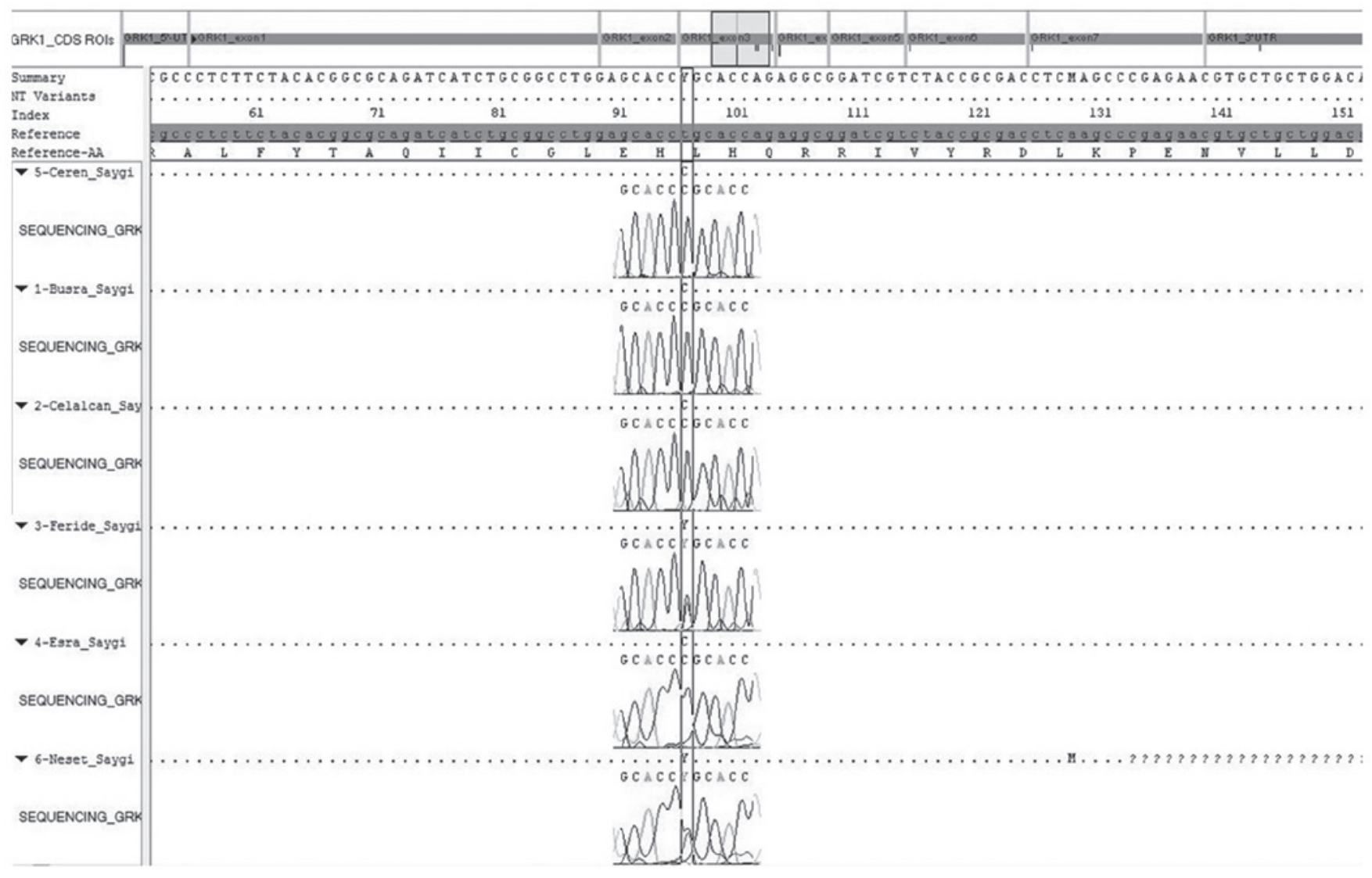

Figure 1. Partial nucleotide sequences of exon 3 of the family. A novel homozygous variation (c.923T >C) is highlighted, resulting in the substitution of leucine (CTG) for proline (CCG) at position 308. Parents were heterozygous for this mutation.

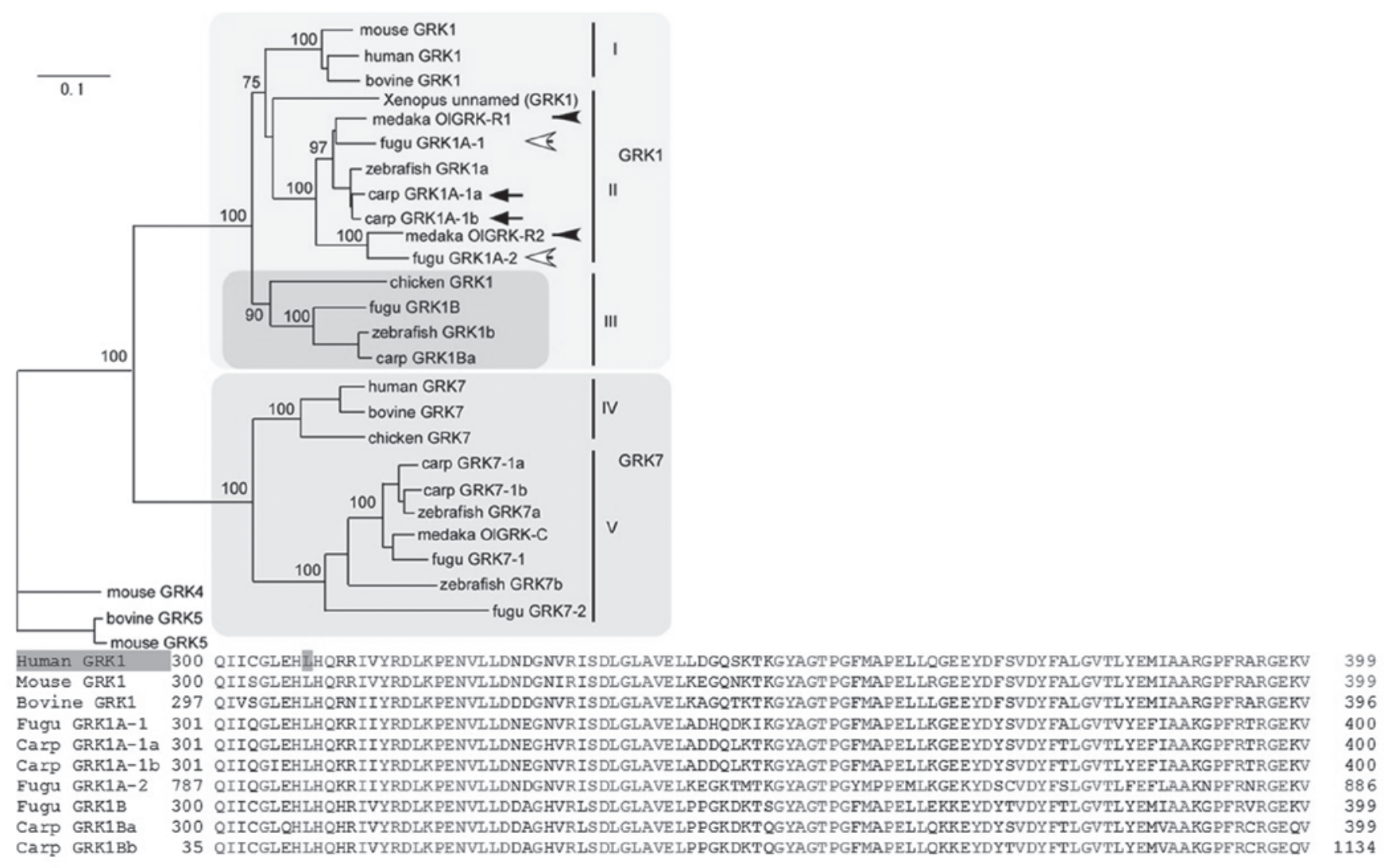

Figure 2. Molecular phylogenetic tree of vertebrate GRK1 genes. Branch length is proportional to the number of amino acid substitutions; the scale bar represents 0.1 amino acid substitutions per position in the sequences. 
and their flanking sequences were analyzed in the 4 siblings and their parents to identify mutations that may be causing Oguchi disease. Sequencing results were analyzed with SeqScape 3 software (Applied Biosystems) by aligning to the Human Reference Genome Sequence (GRCh38/hg38), and single nucleotide variations (SNVs) were determined. The single nucleotide polymorphism (SNP) database dbSNP (build 141) served as a reference for registered SNPs, and non-synonymous SNVs were extracted. Heterozygous and homozygous variations were identified, including de novo heterozygous variations and a homozygous variation, as presented in Table II. Molecular analysis of the $S A G$ gene revealed no SNPs that segregated with the disease. The mutation analysis of the other candidate gene, GRK1, demonstrated a novel mutation (c.923T>C) (Fig. 1), shared by all family members, which was homozygous in all siblings and heterozygous in the two parents, consistent with autosomal recessive transmission (Table II). This novel finding directed us to determine whether this position is conserved phylogenetically among other GRK1 orthologs by utilizing Clustal W2.1 (Conway Institute UCD, Dublin, Ireland). Nucleotide changes resulting in the change of the strictly conserved residue 308 from leucine to proline affects the protein kinase catalytic domain of the gene. Popular bioinformatics tools SIFT and PolyPhen-2 analysis scores ( 0 and 1.000 , respectively) confirm this change to be damaging. Further analysis is required in healthy populations to confirm pathogenicity. No other mutations were found in the GRK1 gene in the patients. The molecular phylogenetic tree of vertebrate $G R K 1$ genes, which are highly conserved, is shown in Fig. 2. Branch length is proportional to the number of amino acid substitutions; the scale bar represents 0.1 amino acid substitutions per position in the sequences. As the branches are short, we can therefore predict damaging effects from the occurrence of amino acid changes (5).

\section{Discussion}

CSNB caused by defective signaling from photoreceptors to bipolar cells is characterized by a reduced or absent b-wave and a normal a-wave in electroretinography (6). Oguchi disease is an uncommon form of CSNB, characterized by specific clinical characteristics, termed the Mizuo-Nakamura phenomenon (7). Two genes are known to be involved in Oguchi disease: $S A G$ and GRK1 gene (7). In a European study, all the reported patients had mutations in GRK1. However, the majority of Japanese patients with Oguchi disease have another causative gene, $S A G(8)$.

$S A G$, also termed arrestin, encodes a major protein of the outer retinal segment. It binds to activated rhodopsin in retinal rod outer segments. Mutations in this gene have previously been associated with Oguchi disease (9). In the present study a novel missense mutation was identified.

The GRK1 gene encodes rhodopsin kinase, responsible for the phosphorylated rhodopsin in rod cells (10). Mutations in GRK 1 can result in the Oguchi phenotype. This study demonstrated that a novel amino acid change (p.Leu308Pro) was common in all siblings in the family in a homozygous state and thus may have resulted in Oguchi disease.

To date, in the Turkish population there have been no reports of GRK1 mutations causing Oguchi disease. In the present study, a novel nonsense mutation in GRK1 in affected members of a consanguineous Turkish family was identified. In conclusion, a novel GRK1 variant (c.923T>C) was shown the be the cause of Oguchi disease in 4 family members who inherited the mutation from a common ancestor of their parents.

\section{References}

1. Malaichamy S, Sen P, Sachidanandam R, Arokiasamy T, Lancelot ME, Audo I, Zeitz C and Soumittra N: Molecular profiling of complete congenital stationary night blindness: A pilot study on an Indian cohort. Mol Vis 20: 341-351, 2014.

2. Yamamoto S, Sippel KC, Berson EL and Dryja TP: Defects in the rhodopsin kinase gene in the Oguchi form of stationary night blindness. Nat Genet 15: 175-178, 1997.

3. Yamamoto H, Simon A, Eriksson U, Harris E, Berson EL and Dryja TP: Mutations in the gene encoding 11-cis retinol dehydrogenase cause delayed dark adaptation and fundus albipunctatus. Nat Genet 22: 188-191, 1999.

4. Waheed NK, Qavi AH, Malik SN, Maria M, Riaz M, Cremers FP, Azam $\mathrm{M}$ and Qamar R: A nonsense mutation in S-antigen (p.Glu306*) causes Oguchi disease. Mol Vis 18: 1253-1259, 2012.

5. Shimauchi-Matsukawa Y, Aman Y, Tachibanaki S and Kawamura S: Isolation and characterization of visual pigment kinase-related genes in carp retina: Polyphyly in GRK1 subtypes, GRK1A and 1B. Mol Vis 11: 1220-1228, 2005.

6. Van Genderen MM, Bijveld MM, Claassen YB, Florijn RJ, Pearring JN, Meire FM, McCall MA, Riemslag FC, Gregg RG, Bergen AA and Kamermans M: Mutations in TRPM1 are a common cause of complete congenital stationary night blindness. Am J Hum Genet 85: 730-736, 2009.

7. Huang L, Li W, Tang W, Zhu X, Ou-Yang P and Lu G: A Chinese family with Oguchi's disease due to compound heterozygosity including a novel deletion in the arrestin gene. Mol Vis 18: 528-536, 2012.

8. Oishi A, Akimoto M, Kawagoe N, Mandai M, Takahashi M and Yoshimura N: Novel mutations in the GRK1 gene in Japanese patients With Oguchi disease. Am J Ophthalmol 144: 475-477, 2007.

9. Goldstein O, Jordan JA, Aguirre GD and Acland GM: A non-stop $\mathrm{S}$-antigen gene mutation is associated with late onset hereditary retinal degeneration in dogs. Mol Vis 19: 1871-1884, 2013.

10. Azam M, Collin RW, Khan MI, Shah ST, Qureshi N, Ajmal M, den Hollander AI, Qamar R and Cremers FP: A novel mutation in GRK1 causes Oguchi disease in a consanguineous Pakistani family. Mol Vis 15: 1788-1793, 2009. 